\title{
Detection of Chlamydia trachomatis by ligase chain reaction compared with polymerase chain reaction and cell culture in urogenital specimens
}

\author{
B de Barbeyrac, P Rodriguez, B Dutilh, P Le Roux, C Bébéar
}

\begin{abstract}
Objective-The aim of this study was to evaluate the newly developed ligase chain reaction (LCR) assay for the detection of Chlamydia trachomatis in urogenital specimens using cell culture and Amplicor ${ }^{T M}$ PCR for comparison. Subjects-Two hundred and eighty patients attending hospital or urban STD clinics (high-risk population, 62 men and 84 women) and obstetric/gynaecology clinics (low-risk population, 134 women) in Bordeaux, France.

Methods-Specimens from men were tested with LCR on urethral swabs and urine, with Amplicor ${ }^{T M}$ on urine, with cell culture on urethral swabs. Specimens from women were tested with $L C R$, Amplicor ${ }^{T M}$ and cell culture on endocervical swabs and with LCR on urine. When the three methods generated different results, the LCR and Amplicor ${ }^{T M}$ tests were repeated on the remaining samples. Samples with discordant LCR and Amplicor ${ }^{T M}$ results and a negative culture were further analysed by major outer membrane protein gene omp1-PCR.

Results-After analysis of discrepant results, the overall prevalence was $7 \cdot 5 \%$ (21/280) calculated on the basis of an expanded "gold standard" defined as culture positive or LCR plus Amplicor $^{T M}$ positive or omp1-PCR positive for discrepant results between LCR and Amplicor ${ }^{T M}$ tests. Of the 21,20 were detected by $L C R$, 17 by $A m p l i c o r{ }^{T M}$ and culture. The specificity of LCR and Amplicor ${ }^{T M}$ was $99 \cdot 6 \%$.

Conclusion-The LCR Chlamydia trachomatis test is a highly sensitive nonculture technique and a good alternative test for the detection of chlamydial infections.
\end{abstract}

Laboratoire de Bactériologie, Hôpital Pellegrin, Place Amélie Raba Léon, 33076 Bordeaux Cedex, France

B de Barbeyrac

P Rodriguez

C Bébéar

Laboratoire d'Analyses Médicales, rue Mandron, 33000 Bordeaux, France B Dutilh

Laboratoires Abbott, rue de la Couture, 94518 Rungis Cedex, France

P Le Roux

Address correspondence to: Dr B de Barbeyrac detection of this organism in the clinical laboratory is essential for the effective treatment and control of spread of infection.
Despite a sensitivity of less than $100 \%$, cell culture is still considered to be the reference method for chlamydia detection. ${ }^{3}$ This technique is time-consuming, labour-intensive and requires trained personnel and optimal conditions of transport and storage of clinical specimens to ensure the chlamydia are alive and infectious. Alternative test methods have been developed in the last decade. However, these non-culture methods, including direct staining using immunofluorescence, enzyme immunoassays and DNA probe techniques, sometimes fail because they lack sensitivity and specificity. ${ }^{4}$ In the last five years, DNA amplification by PCR has been proposed for the diagnosis of $C$ trachomatis urogenital infections, ${ }^{5-9}$ and the Amplicor $C$ trachomatis test has been commercially developed by Roche Molecular Systems (RMS, Branchburg, New Jersey, USA) as a rapid and sensitive test. It combines the PCR technique applied to the $C$ trachomatis cryptic plasmid and a colourimetric microwell DNA hybridisation detection method. ${ }^{10}$ The ligase chain reaction (LCR) test, developed more recently by Abbott Laboratories (Chicago, Illinois, USA), amplifies a double set of primers specific to the cryptic plasmid of $C$ trachomatis, ${ }^{11}$ the amplicons being detected by a microparticle-based sandwich immunoassay. The purpose of this study was to compare the LCR test, the Amplicor ${ }^{T M}$ test, and cell culture for the detection of $C$ trachomatis in urogenital specimens collected from men and women.

Patients and methods

PATIENT POPULATION AND SPECIMEN

COLLECTION

From November 1993 to May 1994218 women and 62 men were enrolled. Patients attended the obstetrics/gynaecology clinics (low risk population, 134 women) at the Pellegrin Hospital, Bordeaux or were seen in consultation in hospital or urban STD clinics (high risk population, 62 men and 84 women). Two urethral swabs were collected from male patients, one swab was placed into a transport medium for culture (consisting of sucrosephosphate buffer (2SP) supplemented with $5 \%$ fetal bovine serum), and the other was placed in the Chlamydia LCR transport medium. Next, a first void urine (FVU) (15 to $20 \mathrm{ml}$ ) was collected in sterile collection cups and aliquotted into two parts for LCR and Amplicor $^{T M}$. An FVU for LCR and three endocervical swabs were collected from female patients. One swab was placed in 2SP for 
culture, one placed in the Chlamydia LCR transport medium, and one into the Amplicor ${ }^{T M}$ specimen transport medium. For both men and women, all swabs were randomly collected. Urine samples could not be obtained from 121 women, and genital specimens were tested alone. No information about previous antibiotic therapy could be obtained.

\section{CHLAMYDIA CELL CULTURE}

Female endocervical and male urethral swabs, in 2SP transport medium, were stored at $-70^{\circ} \mathrm{C}$ until inoculation on to $\mathrm{McCoy}$ cell monolayers. Culture was performed on 280 clinical samples, following a previously described method. ${ }^{12} C$ trachomatis inclusions were detected by using a fluorescein-conjugated monoclonal antibody raised against the major outer membrane protein (Syva Microtrak, Palo Alto, California, USA). Specimens were positive when at least one inclusion could be detected on either the initial or blind pass cultures. The number of inclusions per coverslip was counted.

\section{CHLAMYDIA LCR ASSAY}

Female endocervical $(n=218)$, male urethral swabs $(n=62)$ in LCR transport medium, and uncentrifuged FVU $(n=153)$ from men and women were stored at $-70^{\circ} \mathrm{C}$ until the LCR test was performed. The test was processed following the manufacturer's instructions. FVU specimens were vortexed and $1 \mathrm{ml}$ was centrifuged for 10 minutes at $13,000 \mathrm{~g}$. After removing the supernatant, the pellet was resuspended in $1 \mathrm{ml}$ of the urine resuspension buffer. Treated urine samples and genital swabs in their transport medium were then heated at $95-100^{\circ} \mathrm{C}$ for 15 minutes. After cooling to room temperature, samples were tested immediately by transferring $100 \mu \mathrm{l}$ to a $C$ trachomatis LCR unit dose tube containing $100 \mu \mathrm{l}$ of the LCR reaction mixture. Two positive and two negative controls, as well as two calibrators, were run with each batch of processed samples. The unit dose tubes were subjected to 40 cycles in a Perkin Elmer thermocycler 480 . The amplified products were placed manually in reaction cells and revealed automatically in a modified Abbott IMx analyser. Results were expressed as counts per second per second (c/s/s) with a positive result being defined as equal to or greater than the product of the mean of the two calibrator values times 0.45 .

\section{AMPLICOR $^{\mathrm{TM}}$}

The Amplicor ${ }^{T M} C$ trachomatis PCR test was performed on the 218 endocervical swabs, the 56 male urine samples and six male urethral swabs. Endocervical swabs in Amplicor specimen transport medium were stored at $4^{\circ} \mathrm{C}$. FVU were centrifuged at $2,500 \mathrm{~g}$ for $10 \mathrm{~min}-$ utes at room temperature, the supernatants were discarded and the pellets stored at $-70^{\circ} \mathrm{C}$ until the $A m p l i c o r{ }^{T M}$ was performed as previously described. ${ }^{12}$ Urine pellets were processed following the manufacturer's instructions. Specimens were considered positive when the optical density (OD) values at $450 \mathrm{~nm}$ were greater than 0.5 , and negative when the OD values were less than 0.25 . Specimens with OD values between 0.25 and $0 \cdot 5$ (grey zone) were tested again.

\section{ANALYSIS OF DISCREPANT RESULTS}

Discrepant results were analysed by doing the different tests a second time from the remaining clinical specimens stored at $-70^{\circ} \mathrm{C}$. The specimens were retested by LCR without modification of the initial protocol and by Amplicor $^{T M}$ after ten-fold dilution in Amplicor $^{T M}$ specimen transport medium for swabs or in urine dilution buffer for FVU. Samples with discordant $A m p l i c o r{ }^{T M}$ and LCR results and a negative culture, were submitted to PCR by using primers CT1/CT2 directed against the ompl gene (outer membrane protein) on the 2SP culture transport medium. ${ }^{5}$

\section{STATISTICAL ANALYSIS}

A clinical specimen was considered to be truly positive if either the cell culture was positive or both LCR and $A m p l i c o r^{T M}$ results were positive or omp1-PCR positive when LCR and Amplicor ${ }^{T M}$ gave discordant results. A clinical specimen was considered to be truly negative when the cell culture and at least one of the two other test results were both negative.

\section{Results}

A total of 280 patients were tested by using the three detection methods, LCR, Amplicor ${ }^{T M}$ and cell culture. There was a good correlation among the three techniques, even without arbitration of discrepant results, since 269 of the 280 patients $(96 \%)$ had totally concordant results (table 1). Of these 269 patients, 14 were positive (six men and eight women) and 255 were negative by all the techniques used. Of the 14 patients with concordant positive results, six men had LCR-positive results on both urethral and urine specimens, positiveAmplicor $^{T M}$ on urine and positive-culture results on urethral swabs. Eight women detected as positive for $C$ trachomatis infection had positive LCR, Amplicor ${ }^{T M}$ and culture on endocervical swabs, and four of them had pos- 
Table 2 Arbitration of discrepant $\mathrm{C}$ trachomatis results

\begin{tabular}{|c|c|c|c|c|c|c|}
\hline \multirow[b]{2}{*}{ Case no. / sex } & \multicolumn{6}{|c|}{ Test results } \\
\hline & $\begin{array}{l}\text { Initial } \\
L C R^{\star}\end{array}$ & $\begin{array}{l}\text { Duplicate } \\
L C R^{\star}\end{array}$ & $\begin{array}{l}\text { Initial } \\
\text { Amplicor }^{\mathrm{TM}}\end{array}$ & $\begin{array}{l}\text { Duplicate } \\
\text { Amplicor }^{\mathrm{TM}}\end{array}$ & $\begin{array}{l}\text { Culture } \\
\text { (number of } \\
\text { inclusions } \\
\text { per slip) }\end{array}$ & $\begin{array}{l}\text { omp 1-PCR } \\
\text { on } 2 S P \\
\text { medium }\end{array}$ \\
\hline $\mathbf{1} / \mathbf{M}+$ & $+1+$ & ND & - & + & - & + \\
\hline $2 / \mathrm{M} \dagger$ & $+1+$ & ND & - & + & $+(10)$ & ND \\
\hline $3 / \mathrm{Ft}$ & + ND & $+/ \mathrm{ND}$ & - & + & - & + \\
\hline $4 / F \ddagger$ & $+\mathrm{ND}$ & $-\mathbb{N D}$ & - & - & - & - \\
\hline $5 / \mathrm{Ft}$ & $+1+$ & ND & - & + & $+(5)$ & ND \\
\hline $6 / \mathrm{M} \dagger$ & $+1-$ & $+1+$ & + & ND & $+(20)$ & ND \\
\hline $7 / \mathrm{M} \dagger$ & $+1+$ & ND & + & ND & - & - \\
\hline $8 / F \ddagger$ & $-1-$ & $-1-$ & + & + & - & - \\
\hline $9 / \mathrm{Ff}$ & $-1-$ & $+1-$ & + & + & - & - \\
\hline $10 / F \ddagger$ & $-1+$ & $-1+$ & - & - & - & - \\
\hline $11 / \mathrm{F} \ddagger$ & $-\mathbb{N D}$ & $-\mathbb{N D}$ & grey zone & - & - & ND \\
\hline
\end{tabular}

itive LCR on urine. The number of inclusions detected on coverslips in the culture positive specimens varied from between one and more than 500 .

Table 2 shows the detailed results obtained for the 11 patients (four men and seven women) presenting discrepant results among the three techniques used or among results obtained on different samples from the same patient. Of these, four were considered to be truly positive according to our criteria, before arbitration of discrepant results (cases 2, 5, 6, 7). Of these four, three were confirmed after a duplicate LCR (case 6) or a duplicate Amplicor ${ }^{T M}$ (cases 2 and 5). In case 3, the positive LCR result was confirmed by the duplicate Amplicor $^{T M}$ result and by omp1-PCR on 2SP culture medium contrary to case 4 . This latter case is considered to be false LCRpositive, and the case 8 as false Amplicor $^{T M_{-}}$ positive according to our criteria. In case 9, the duplicate LCR result was positive on the endocervical specimen, but was still negative on the FVU. Interestingly; in case 10 , positive results were only obtained on the FVU by LCR while the three techniques gave negative results on the endocervical swabs. The urine data were excluded from the statistical analysis and a woman was considered infected or not based on the results of cervical specimens. In case 11, the first Amplicor $^{T M}$ result gave an OD value in the grey zone $(0.409)$. This specimen was considered to be truly negative after dilution and retesting. False negative culture results were obtained in cases $1,3,7$ and 9. In order to resolve culture discrepancies, omp1PCR was performed on the 2SP transport

Table 3 Comparison of LCR, Amplicor ${ }^{\mathrm{TM}}$ and culture according to initial test results after resolution of discrepancies

\begin{tabular}{|c|c|c|c|c|}
\hline \multirow[b]{2}{*}{ Tests and results } & \multicolumn{4}{|c|}{ No of resolved specimens } \\
\hline & Positive & Negative & Sensitivity & Specificity \\
\hline \multicolumn{5}{|l|}{ LCR } \\
\hline Positive & 20 & 1 & $95 \cdot 2 \%$ & \\
\hline $\begin{array}{c}\text { Negative } \\
\text { Amplicor }^{T M}\end{array}$ & 1 & 258 & & $99 \cdot 6 \%$ \\
\hline Positive & 17 & 1 & $80 \cdot 9 \%$ & \\
\hline $\begin{array}{l}\text { Negative } \\
\text { Culture }\end{array}$ & 4 & 258 & & $99 \cdot 6 \%$ \\
\hline Positive & 17 & 0 & $80 \cdot 9 \%$ & \\
\hline Negative & 4 & 259 & & $100 \%$ \\
\hline
\end{tabular}

medium. In cases 1 and 3, the positive omp1PCR results confirmed the results of Amplicor $^{T M}$ and LCR contrary to cases 7 and 9.

After analysis of discrepant results, seven patients were finally considered as true positive (cases 1, 2, 3, 5, 6, 7 and 9), and four as true negative cases (cases $4,8,10$ and 11 ). The overall prevalence was $7 \cdot 5 \%(21 / 280)$ and detailed prevalences in the different populations tested were $2 \cdot 2 \%$ in women with low risk of infection, $12.3 \%$ for patients with high-risk of infection $(16.1 \%$ in men and $9.5 \%$ in women). Of these 21 patients, 20 were detected by LCR, 17 by Amplicor ${ }^{T M}$ and culture. When considering only the initial results, LCR, cell culture and Amplicor ${ }^{T M}$ had sensitivities of $95.2,80.9$, and $80.9 \%$ respectively (table 3). When the duplicate tests were considered, LCR and PCR tests gave equivalent results with a sensitivity of $100 \%$ and a specificity of $99 \cdot 6 \%$.

\section{Discussion}

New diagnostic assays using molecular techniques have been developed, especially to diagnose and control STDs. Because of the better sensitivity of these tests, DNA amplification has been used on organisms that are difficult or impossible to culture. ${ }^{1}$ PCR and LCR techniques have been applied on $C$ trachomatis and are now (Amplicor ${ }^{T M}$ ) or will soon (L) be commercially available. The new $\mathrm{LC}_{2} \mathrm{R}$ test has been evaluated in our laboratory, on genital and urine specimens from both men and women. The LCR results have been compared with those obtained using Amplicor $^{T M}$ and cell culture. The overall LCR sensitivity was $95 \cdot 2 \%$, and its specificity was $99.6 \%$. Previous data on LCR performed on urogenital specimens ${ }^{13-15}$ reported sensitivities from 81 to $100 \%$, and specificities from 93.5 to $100 \%$ depending on the specimens. The sensitivity and specificity values and the differences between the tests observed in our study, cannot be generalised because there were too few positive specimens. Differences in sensitivity are usually even more pronounced in low-risk than in high-risk population and the overall sensitivity is lower in specimens from males than from females. ${ }^{4}$ 
Most of the initial discrepancies of LCR and Amplicor $^{T M}$ tests were resolved by repeating the tests. Six initially false negative results (four Amplicor ${ }^{T M}$ and two LCR tests) were modified by diluting the samples or after freezing at $-70^{\circ} \mathrm{C}$. It has been shown that the polymerase and ligase enzymes are more or less sensitive to inhibitors that decrease after a few days of storage or dilution of clinical samples. ${ }^{12}{ }^{14-16}$ The problem of inhibitors is of utmost importance in comparison with those of sensitivity. Indeed, a sensitivity evaluation test of LCR and Amplicor ${ }^{T M}$, performed in our laboratory on a diluted $C$ trachomatis strain, showed that LCR and Amplicor $^{T M}$ were at least as sensitive as culture, detecting one inclusion forming unit. Moreover, no correlation between the results of the molecular techniques and the quantitative results of culture was found. Furthermore, when the duplicate tests were considered, LCR and Amplicor ${ }^{T M}$ gave equivalent results with a sensitivity of $100 \%$. Future improvements in molecular techniques should strive to eliminate polymerase inhibition.

In case 4 , a positive LCR result was initially obtained that was negative by duplicating the tests. The specimen was negative by all three techniques. The reason why this first LCR test was positive is unclear. As the evaluation of the $C$ trachomatis LCR technique was performed using the prototype version, samples were manually dispensed into the IMx reaction cells for the final detection. During this step, cross-contamination of the samples was possible and could explain an initial positive and a duplicate negative test result.

Concerning the four false negative culture results, two (cases 7 and 9) may be explained by sampling variability due to the number of samples performed on the same patient. For cases 1 and 3, the ompl-PCR control performed on the culture transport medium was found to be positive. This may have resulted from an infected patient who had been treated, or an infected patient with extremely low numbers of viable organisms not detectable in culture because of conditions of specimen collection or transport. ${ }^{1}$

Furthermore, Lin et al ${ }^{17}$ have shown that culture results are highly dependent on procedures used to store specimens (time, temperature) and also the technique used for inoculation (vortexing, sonicating, blind passage). In our laboratory, $C$ trachomatis cultures are performed twice a week. Clinical specimens are kept at $-70^{\circ} \mathrm{C}$ until inoculation on to $\mathrm{McCoy}$ cells. Frozen storage has been shown to decrease $11 \%$ of the positive cultures and $68 \%$ of the isolation rate for specimens with less than 50 inclusions forming units per swab. ${ }^{17}$

Only a small number of techniques have been demonstrated to be suitable for the detection of $C$ trachomatis in urine. Urine culture as well as enzyme immunoassays performed on female FVU is very insensitive. ${ }^{1418}$ Amplicor $^{T M}$ has proved to be convenient for the detection of $C$ trachomatis in males. ${ }^{19}{ }^{20}$ In our study, LCR results on male urine samples were almost identical to those obtained with urethral swabs by the same technique (except case 6). With Amplicor ${ }^{T M}$, a duplicate test was necessary for cases 1 and 2. After resolution of discrepancies, the results obtained on male urethral and urine samples were in complete agreement. In another study, ${ }^{21}$ LCR assay of male FVU was much more sensitive than culture of a urethral swab. Of the 97 cases where LCR was performed on female urines and endocervical swabs, the results were in agreement except for two cases (cases 9,10). These cases may be explained by there being only urethral or cervical $C$ trachomatis localisations. Infections localised only in the urethra have been reported in a range of 5 to $30 \%$ of infected women and cervical infections alone in about $30 \% .{ }^{15}$ It would be possible to resolve the cases with positive LCR results only from urines by a confirmatory LCR, using probes targeting another sequence on the plasmid or directed to the major outer membrane protein gene, as described by Schachter et al. ${ }^{14}$ In a recent study, ${ }^{22}$ LCR assay performed on urine samples showed a detection rate almost $30 \%$ greater than that of endocervical swab culture.

In conclusion, both LCR and PCR tests appear to be promising for the diagnosis of $C$ trachomatis infections in the urogenital tract from men and women. The LCR is a simple, rapid and easy to perform test. However, both LCR and Amplicor ${ }^{T M}$ tests will become truly reliable when they are entirely automated, avoiding any potential contamination of the clinical samples. Similarly, to avoid false-negative results due to inhibitors present in the samples, an internal control monitoring the effectiveness of the reaction (LCR or PCR) will be necessary.

We thank Drs M Géniaux, D Dallay, J Horowitz, J J Leng, C Hocke for the collection of specimens.

1 Quinn TC. Recent advances in diagnosis of sexually transmitted diseases. Sex Trans Dis 1994;21:S19-S27.

2 Taylor-Robinson D. Genital chlamydial infections: clinical aspects, diagnosis, treatment and prevention. In: Harris JRW, Forster SM (ed) Recent Advances in Sexually Transmitted Diseases and AIDS. Edinburgh: Churchill Livingstone 1991:219-62.

3 Schachter J, Stamm WE, Chernesky MA, et al. Nonculture tests for genital tract chlamydial infection. What does the package insert mean, and will it mean the same thing tomorrow ? Sex Trans Dis 1992;19:243-4

4 Taylor-Robinson $D$. The value of non-culture techniques for diagnosis of Chlamydia trachomatis infections: making the best of a bad job. Eur $\mathcal{f}$ Clin Microbiol Infect Dis 1992;11:499-503.

5 Dutilh B, Bébéar C, Rodriguez P, Vekris A, Bonnet J, Garret $M$. Specific amplification of a DNA sequence common to all Chlamydia trachomatis serovars using polymerase chain reaction. Res Microbiol 1989;140:7-16.

6 Griffais R, Thibon M. Detection of Chlamydia trachomatis by the polymerase chain reaction. Res Microbiol by the polymer.

7 Näher H, Drzoneck H, Wolf J, von Knebel Doeberitz M, Petzold D. Detection of Chlamydia trachomatis in urogenital specimens by polymerase chain reaction. Genitourin Med 1991;67:21 1-4.

8 Ossewaarde JM, Rieffe $M$, Rozenberg-Arska $M$, Ossenkoppele PM, Nawrocki RP, van Loon AM. Development and clinical evaluation of a polymerase chain reaction test for detection of Chlamydia trachomatis. f Clin Microbiol 1992;30:2122-8.

9 Ostergaard L, Birkelund S, Christiansen G. Use of the polymerase chain reaction for detection of Chlamydia trachomatis. F Clin Microbiol 1990;28:1254-60.

10 Loeffelfolz MJ, Lewinski CA, Silver SR, et al. Detection of Chlamydia trachomatis in endocervical swabs by poly-
merase chain reaction. $\mathcal{f}$ Clin Microbiol 1992;30:2847-51.

11 Dille BJ, Butzen CC, Birkenmeyer LG. Amplification of Chlamydia trachomatis DNA by ligase chain reaction. $\mathcal{f}$ Clin Microbiol 1993;31:729-31. 
12 de Barbeyrac B, Pellet I, Dutilh B, et al. Evaluation of the Amplicor Chlamydia trachomatis test versus culture in genital samples in various prevalence populations. Genitourin Med 1994;70:162-6.

13 Arremark I, Burczak J, Ericsson B, et al. Detection of Chlamydia trachomatis infection with the DNA-technique ligase chain reaction (LCR) in comparison to culture. In: Orfila J, Byrne GI, Chernesky MA, Grayston JT, Jones RB, Ridgway GL, Saikku P, Schachter J, Stamm WE, and Stephens RS (ed): Chlamydial Infections. Proceedings of the Eighth International Symposium on Human Chlamydial Infections. Società Editrice Esculapio, Bologna, 1994:358-61.

14 Schachter J, Stamm WE, Quinn TC, Andrews W, Burczak JD, Lee HH. Ligase chain reaction to detect Chlamydia $\mathrm{JD}$, Lee HH. Ligase chain reaction to detect Chlamydia
trachomatis infection of the cervix. $\mathcal{f}$ Clin Microbiol

15 Chernesky MA, Jang D, Lee $\mathrm{HH}$, et al. Diagnosis of Chlamydia trachomatis infections in men and women by testing first-void urine by ligase chain reaction. $\mathcal{F}$ Clin Microbiol 1994;32:2682-5.

16 Bauwens JE, Clark AM, Stamm WE. Diagnosis of Chlamydia trachomatis endocervical infections by a commercial polymerase chain reaction assay. $f$ Clin Microbiol 1993;31:3023-7.
17 Lin JSL, Jones WE, Yan L, et al. Underdiagnosis of Chlamydia trachomatis infection. Diagnostic limitations in patients with low-level infection. Sex Trans Dis 1992;19:259-65.

18 Bassiri M, Hu HY, Domeika MA, et al. Detection of Chlamydia trachomatis in urine specimens from women by ligase chain reaction. $f$ Clin Microbiol 1995;33: $898-900$.

19 Bianchi A, Scieux C, Brunat N, et al. An evaluation of the polymerase chain reaction Amplicor Chlamydia trachomatis in male urine and female urogenital specimens. Sex Trans Dis 1994;21:196-200.

20 Jaschek G, Gaydos CA, Welsh LE, Quinn TC. Direct detection of Chlamydia trachomatis in urine specimens from symptomatic and asymptomatic men by using a rrom symptomatic and asymptomatic men by using a rapid polymerase

21 Chernesky MA, Lee HH, Schachter J, et al. Diagnosis of Chlamydia trachomatis urethral infection in symptomatic and asymptomatic men by testing first-void urine in a ligase chain reaction assay. $\mathcal{F}$ Infect Dis 1994;170:1308-11.

22 Lee $\mathrm{HH}$, Chernesky MA, Schachter J, et al. Diagnosis of Chlamydia trachomatis genitourinary infection in women by ligase chain reaction assay of urine. Lancet 1995; 345:213-6. 